\section{orin}

OAK RIDGE

NATIONAL

LABORATORY

MARTHN MAREITRA

C/ORNL 920150

\section{RECIPROCATING SLIDING WEAR OF IN-SITU REINFORCED SILICON NITRIDE}

\author{
C. S. Yust
}

Oak Ridge National Laboratory

\author{
AlliedSignal
}

Approved for Public release;

distribution is unlimited.

\section{MANAGED BY}

MARTIN MARIETTA ENERGY SYSTEMS, INC.

FOR THE UNITED STATES

DEPARTMENT OF ENERGY 
Date: $\quad$ December 13, 1994

To: $\quad$ Frank V. Damiano, 6026-E, MS-6396

cc: $\quad$ R. A. Bradley, A. Choudhury, L. B. Dunlap

From: C. S. Yust, 4515, MS-6063 (4-4812) CSy

Subject: Completed CRADA ORNL 92-0150

Enclosed are three copies of the final report for CRADA ORNL 92-0150. I also included a copy of a letter from R. G. Rateick, Jr., stating that this investigation of AlliedSignal silicon nitrides does not constitute Protected CRADA Information, that information disclosed and developed during performance of the CRADA does not contain proprietary information, and that public distribution of the final report is acceptable. 
September 26, 1994

Charley Yust

Oak Ridge National Laboratory

Bldg 4515

1 Bethel Valley Rd.

Oak Ridge TN 37831-6062

Dear Charley:

This letter is in response to your request for information regarding the Status of Completed CRADA's memo.

The results of the investigation of wear of AlliedSignal Silicon Nitrides do not constitute Protected CRADA Information. Further, as identified at the start of the CRADA, public distribution of the final report is acceptable. The information disclosed and developed during the performance of this CRADA does not contain proprietary information.

Sincerely,

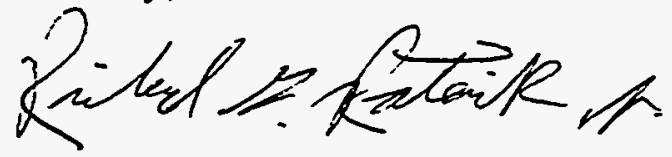

Richard G. Rateick, Jr., P.E.

Senior Engineer

219/231-4311

FAX 219/231-4330

rateick@asca.aro.allied.com

cc: K. Karasek 


\title{
Reciprocating Sliding Wear of In-Situ Reinforced Silicon Nitride
}

\author{
C. S. Yust \\ Metals and Ceramics Division \\ Oak Ridge National Laboratory
}

The reciprocating sliding wear response of two in-situ reinforced-silicon nitride compositions provided by AlliedSignal have been evaluated. The materials were prepared by AlliedSignal- Ceramic Components Division and were tested at conditions of interest to the Bendix Engine Controls Division (South Bend, IN) and AlliedSignal Research and Technology (Des Plaines, $\mathrm{L}$ ). The materials are being considered for a variety of new applications, and the current tests provide critical friction and wear values under anticipated operating conditions. Both pin and disk specimens of GS-44 and GN-10 in-situ reinforced silicon nitride of specified dimensions for wear testing were provided by the AlliedSignal participants. An initial series of tests examined the unlubricated behavior of these mateials at elevated temperature (up to $900 \mathrm{C}$ ) in an inert atmosphere. The results revealed excessive levels of both friction and wear in the unlubricated condition. The test conditions were modified to include the use of jet fuel as a lubricant because of an intended application in that medium. The introduction of the lubricant resulted in very limited wear of both the pin and disk specimens.

\section{Test Procedure and Materials}

The tests were performed in a high temperature pin-on-disk apparatus. In this system, the disk specimen is positioned horizontally against a rotating drive and held in place by a clamping ring. The counterface pin is held at the end of a vertical rod. Both the rod and the rotating mechanism are parts of assemblies that move along a vertical axis. Both pin and disk can be brought into contact at the center of the furnace, which is capable of bringing the system to $1000 \mathrm{C}$. Force applied to the rod by dead-weight loading generates a contact stress at the sphere-disk interface. The applied force was chosen to provide contact pressures at the sliding interface characteristic of the intended applications. In the lubricated tests, contact pressures up to $890 \mathrm{MPa}$ were used.

The rod is seated in a strain-gaged fixture that senses both vertical and lateral motions of the rod. The system of strain gages detects both the normal and tangential forces acting at the interface. These values yield the friction coefficient as a function of time. An electronic data acquisition system was used to provide high rates of data collection, yielding information on the friction variation during individual cycles of sliding.

The disk drive mechanism rotates in either direction or oscillates over controlled arc lengths. In the present tests, oscillatory motion over an arc length of 90 degrees was used to simulate the proposed applications. Sliding velocities were established by varying the frequency of reciprocation over an arc of 90 degrees. The frequency was controlled by imposing a sinusoidal voltage on a position-sensitive detector affixed to the system motor. The test system configuration is illustrated in Fig 1. 
Test durations were varied to investigate the effect of increased periods of reciprocation on both the amount and mechanism of wear. The longest test duration was 6 hours. The lubricant used was Philjet A with PFA MB, a jet engine fuel. This fuel is composed principally of paraffinic hydrocarbons (approx $50 \%$ by wt), naphthenes (33\%) and aromatic hydrocarbons $(17 \%)$. The tests performed and conditions applied are summarized in Table I.

The GS-44 and GN-10 specimens provided by AlliedSignal were in the form of disks, $40 \mathrm{~mm}$ in diameter and $6.35 \mathrm{~mm}$ in thickness and spherically-capped pins, $6.35 \mathrm{~mm}$ in diameter and $25.4 \mathrm{~mm}$ in length. The disk and pin cap surfaces were machined to a surface roughness $\mathrm{Ra} 40$ micrometers. The radius of curvature of the pin caps was $0.5 \mathrm{in}$.

\section{Test Results}

\section{Unlubricated Tests}

The initial tests were performed on GS-44 specimens without the use of a lubricant. Two tests were done at room temperature, one with an applied force of $9.8 \mathrm{~N}$, the other with $0.98 \mathrm{~N}$ applied. The corresponding contact pressures were, respectively, $680 \mathrm{MPa}$ and $315 \mathrm{MPa}$. In both cases, the friction coefficient values recorded during the test were in the range of 0.8 to 0.9 . A third test at $900 \mathrm{C}$ at an applied force of $9.8 \mathrm{~N}$. also resulted in friction coefficient values of 0.9 . The $680 \mathrm{MPa}$ contact pressure resulted in very heavy wear and formation of a deep wear groove. At $315 \mathrm{MPa}$, a smaller wear scar was produced, but the amount of wear associated with the load and duration of the test was greater than was acceptable. The wear track formed in the $900 \mathrm{C}$ test is shown in an optical micrograph in Fig. 2. The depth of the wear groove after 3.75 hours of sliding at a contact pressure of $680 \mathrm{MPa}$ at $900 \mathrm{C}$ in air was too large to be measured by the profilometer. The room temperature specimen was measured after 1 hour of sliding at the same contact pressure and the corresponding wear track profile is shown in Fig. 3. The wear groove depth was 40 microns at the center. The excessive wear encountered in the unlubricated sliding of GS-44 on itself led to a cancellation of further unlubricated testing.

\section{Lubricated Tests}

In contrast to the unlubricated tests, the tests utilizing jet fuel as a lubricant resulted in very limited wear of both GN-10 and GS-44 specimens. The machining marks on the disk specimen surfaces are a sensitive indicator of the amount of material removed from the surface. If the machining marks are not completely removed, the wear depth is less than the original surface roughness height. In experiments at the highest load and velocity, and at the longest test duration, machining marks were clearly in evidence within the resultant wear tracks. Because of this limited amount of wear, testing was done primarily at the highest loads and velocities attainable in the test system.

The specific amount of material removed from the wear track surface was determined by surface profilometry. Profilometer traces of the surface were made across the wear tracks perpendicular to the lay of the surface machining marks, where possible. The visual appearance of the track formed on a GS-44 specimen after 6 hours of reciprocating sliding at a contact pressure of $890 \mathrm{MPa}$ is shown in Fig. 4. Machining marks remain within the wear path, and the corresponding track profile, Fig. 5, confirms that wear has not progressed beyong the depth of the original surface roughness. At the center of the wear path the profile indicates some filling of the valleys, probably by wear debris. This profile trace does not correspond to the part of the track shown in the photo. 
In some instances, the position of the wear track on the specimen did not allow a measurement exactly perpendicular to the machining marks, and in those instances the trace was made as nearly perpendicular to the marks as possible. The wear track formed on a GN-10 specimen by 6 hours of sliding at a contact pressure of $890 \mathrm{MPa}$, for example, was perpendicular to the lay of the machining marks, Fig. 6 . In this instance, the profile trace was necessarily made nearly parallel to the lay of the machining marks, resulting in the profile shown in Fig. 7. The depth of the wear track can be seen in the profile, as can a difference in the appearance of the unworn profile as compared to that of Fig. 5 . As the angle between the profile trace and the machining marks diverges from 90 degrees, the profile peaks and valleys become increasingly broader and more widely spaced. The variation in profile peak density with direction did not prevent a realistic assessment of the depth of the wear tracks.

A quantitative measure of the amount of material loss can be obtained by comparing the size of the area beneath the surface profile and a reference line, as, for example, the area between the profile and the mean line in the distance interval 1.8 to $2.4 \mathrm{~mm}$ in Fig. 5, in both the worn and unworn areas. The difference represents the volume loss at the surface. Compare the worn and unworn portions of the profiles in Fig 5 and 7. In both profile figures, the bottom of the wear track has been positioned to be aligned with the mean line of the profile. If the portion of the profile between the distances of $1.8 \mathrm{~mm}$ and $2.4 \mathrm{~mm}$ is isolated, the area beneath the profile referenced to the zero line in this length of $0.6 \mathrm{~mm}$ is found to be $4.6 \mathrm{E}-05 \mathrm{~mm} 2$, or $7.7 \mathrm{E}-05 \mathrm{~mm} 2 / \mathrm{mm}$ of profile length. Similarly, the area beneath remainder of the profile is found to be $7.7 \mathrm{E}-04 \mathrm{~mm} 2$, or $3.2 \mathrm{E}-04 \mathrm{~mm} 2 / \mathrm{mm}$. The loss of material is thus $2.4 \mathrm{E}-04 \mathrm{~mm} 2 / \mathrm{mm}$, or $1.5 \mathrm{E}-04 \mathrm{~mm} 2$ for the $0.6 \mathrm{~mm}$ wide wear scar. The wear scar length is $14 \mathrm{~mm}$, consequently the total wear volume is $2.1 \mathrm{E}-3 \mathrm{~mm} 3$. For the applied force of $21.9 \mathrm{~N}$ and total sliding distance of $750 \mathrm{~m}$, the wear shown in Fig 5 is equivalent to a wear factor of $1.3 \mathrm{E}-07 \mathrm{~mm} 3 / \mathrm{N} . \mathrm{m}$. Similar considerations for the wear scar of Fig 7 yield a wear factor of $2.3 \mathrm{E}-07 \mathrm{~mm} 3 / \mathrm{N}$.m. These wear factor estimates do not take the initial transient wear period into account and therefore exaggerate the wear factor value. Nevertheless, the values are consistent with the observation of very limited wear.

The typical wear scar formed on the pin tip is shown in Fig. 8. A wear flat has formed on the spherical surface, and some abrasion marks are evident on the worn surface. The radiating marks surrounding the flat are formed by the intersection of the wear surface with the machining marks on the pin tip.

Normal and tangential force values were recorded periodically during each experiment, yielding friction coefficient values. Fig. 9 illustrates the variation of friction coefficient during one cycle of reciprocating motion in the unlubricated test at $900 \mathrm{C}$ in air. At the start of the test, friction coefficient values were in the range of 0.3 to 0.4. After thirty minutes of reciprocating motion, the friction coefficient had increased to about 0.9 , and it remained at this value for the remainder of the test. In the lubricated tests, friction coefficient values were in the range of 0.15 to 0.2 , see Table I.

\section{Summary}

Specimens of GS-44 and GN-10 insitu-reinforced silicon nitiride have been tested with and without lubrication. A pin-on-disk test configuration, using reciprocating sliding motion, was used. In the unlubricated mode, heavy wear was produced at a contact pressure of $680 \mathrm{MPa}$ in one hour at room temperature. At $900 \mathrm{C}$ in air under a contact pressure of $680 \mathrm{MPa}$, very heavy wear was also observed. The use of a jet fuel as a 
lubricant, however, resulted in sliding wear for periods of up to 6 hours at a contact pressure of $890 \mathrm{MPa}$ without causing wear tracks deeper than the original surface roughness of the specimen. The average sliding velocity in these latter tests was $35 \mathrm{~mm} / \mathrm{s}$. The results of the lubricated tests suggest that useful service life may be expected of GS-44 and GN-10 components limited to contact pressures of 800-900 Mpa in appropriately lubricated environments. 
Table I

Summary of Test Variables and Results

\begin{tabular}{|c|c|c|c|c|c|c|c|c|}
\hline Run No. & $\begin{array}{l}\text { GS-44 } \\
\text { GS-44 } \\
\text { GS-44 }\end{array}$ & $\begin{array}{l}\text { Contact } \\
\text { Pressure } \\
\text { (MPa) } \\
680 \\
315 \\
680\end{array}$ & $\begin{array}{l}\text { Velocity } \\
(\mathrm{mm} / \mathrm{s}) \\
15.0 \\
15.0 \\
15.0\end{array}$ & $\begin{array}{l}\text { Duration } \\
\text { (hours) } \\
1 \\
15.8 \\
3.8\end{array}$ & $\begin{array}{l}\text { Temp. } \\
(C) \\
20 \\
20 \\
900\end{array}$ & $\begin{array}{l}\text { None } \\
\text { None } \\
\text { None }\end{array}$ & $\begin{array}{l}\text { Friction } \\
\text { Coeff. } \\
\\
0.85 \\
0.80 \\
0.90\end{array}$ & $\begin{array}{l}\text { Heavy } \\
\text { Moderate } \\
\text { Heavy }\end{array}$ \\
\hline $\begin{array}{l}06 \\
07 \\
08 \\
09 \\
10 \\
11 \\
12\end{array}$ & $\begin{array}{l}\text { GN-10 } \\
\text { GN-10 } \\
\text { GS-44 } \\
\text { GS-44 } \\
\text { GS-44 } \\
\text { GN-10 } \\
\text { GN-10 } \\
\text { GS-44 }\end{array}$ & $\begin{array}{l}860 \\
860 \\
860 \\
860 \\
860 \\
860 \\
890 \\
890\end{array}$ & $\begin{array}{l}13.4 \\
13.4 \\
13.4 \\
13.4 \\
35.0 \\
35.0 \\
35.0 \\
35.0\end{array}$ & $\begin{array}{l}0.5 \\
3.0 \\
0.5 \\
3.0 \\
3.0 \\
3.0 \\
6.0 \\
6.0\end{array}$ & $\begin{array}{l}20 \\
20 \\
20 \\
20 \\
20 \\
20 \\
20 \\
20\end{array}$ & $\begin{array}{l}\text { Jet Fuel } \\
" \\
" 1 \\
" \\
" 1 \\
"\end{array}$ & \begin{tabular}{l}
$0.19-0.16$ \\
$0.19-0.20$ \\
\hdashline$\ldots .15$ \\
0.18 \\
$0.19-0.14$ \\
$\cdots \ldots$ \\
$\cdots .$.
\end{tabular} & $\begin{array}{l}\text { Very Mild } \\
\text { " } \\
" 1 \\
" 1 \\
" 1 \\
"\end{array}$ \\
\hline
\end{tabular}




\section{Figure Captions}

Fig. 1. Schematic diagram of the high temperature tribotest system. A. pin specimen, B. disk specimen, C. base plate for specimen stage, D. mounting rod for pin specimen, E. dead weight, $F$. resistance heating coils, $G$. gold-coated reflector, $H$. insulating plate, $I$. water cooling for the base plate, J. drive motor, $\mathrm{K}$. aluminum base plate for the machine, L. glass bell jar.

Fig. 2. Optical micrograph of the wear groove formed in an unlubricated test of GS-44 at $900 \mathrm{C}$ in air. Wear debris is evident along the sides of the wear track and as accumulations at each end of the track.

Fig. 3. Profile of a wear groove similar to that shown in Fig. 2, but formed by 1 hour of reciprocating sliding at room temperature The groove depth at the center of the wear track is 40 microns.

Fig 4. Optical micrograph of the wear track formed on GS-44 after 6 hours of lubricated reciprocating sliding at a contact pressure of $890 \mathrm{MPa}$. The peaks of the machined profile have been flattened in the wear track, but many of the initial profile valleys remain.

Fig. 5. The profile trace of the wear track shown in Fig. 4 confirms that the track depth is not greater than the original surface roughness. The trace also shows some filling of the profile valleys at the center of the wear track. This trace is not from the same area as the photo.

Fig. 6. Optical micrograph of the wear track formed on GN-10 after 6 hours of lubricated reciprocating sliding at a contact pressure of $890 \mathrm{MPa}$. The peaks and valleys of the original profile are plainly seen in this orientation of the wear track with respect to the machining direction.

Fig. 7. The profile trace of the wear track shown in Fig. 6. The wear track depth is not deeper than the original surface roughness, and some wear track valley are again filled by debris at the center of the track.

Fig. 8 Typical wear flat formed on the pin specimen in the lubricated tests. The intersection of the wear flat with the pin tip machining marks forms the radiating pattern surrounding the scar.

Fig. 9. Plot of the variation of friction coefficient during one cycle of reciprocating motion for the unlubricated test of GS-44 at $900 \mathrm{C}$ in air. After 30 minutes of sliding, the friction coefficient has reached the value maintained for the remainder of the test.

\section{DISCLAIMER}

\footnotetext{
This report was prepared as an account of work sponsored by an agency of the United States Government. Neither the United States Government nor any agency thereof, nor any of their employees, makes any warranty, express or implied, or assumes any legal liability or responsibility for the accuracy, completeness, or usefulness of any information, apparatus, product, or process disclosed, or represents that its use would not infringe privately owned rights. Reference herein to any specific commercial product, process, or service by trade name, trademark, manufacturer, or otherwise does not necessarily constitute or imply its endorsement, recommendation, or favoring by the United States Government or any agency thereof. The views and opinions of authors expressed herein do not necessarily state or reflect those of the United States Government or any agency thereof.
} 


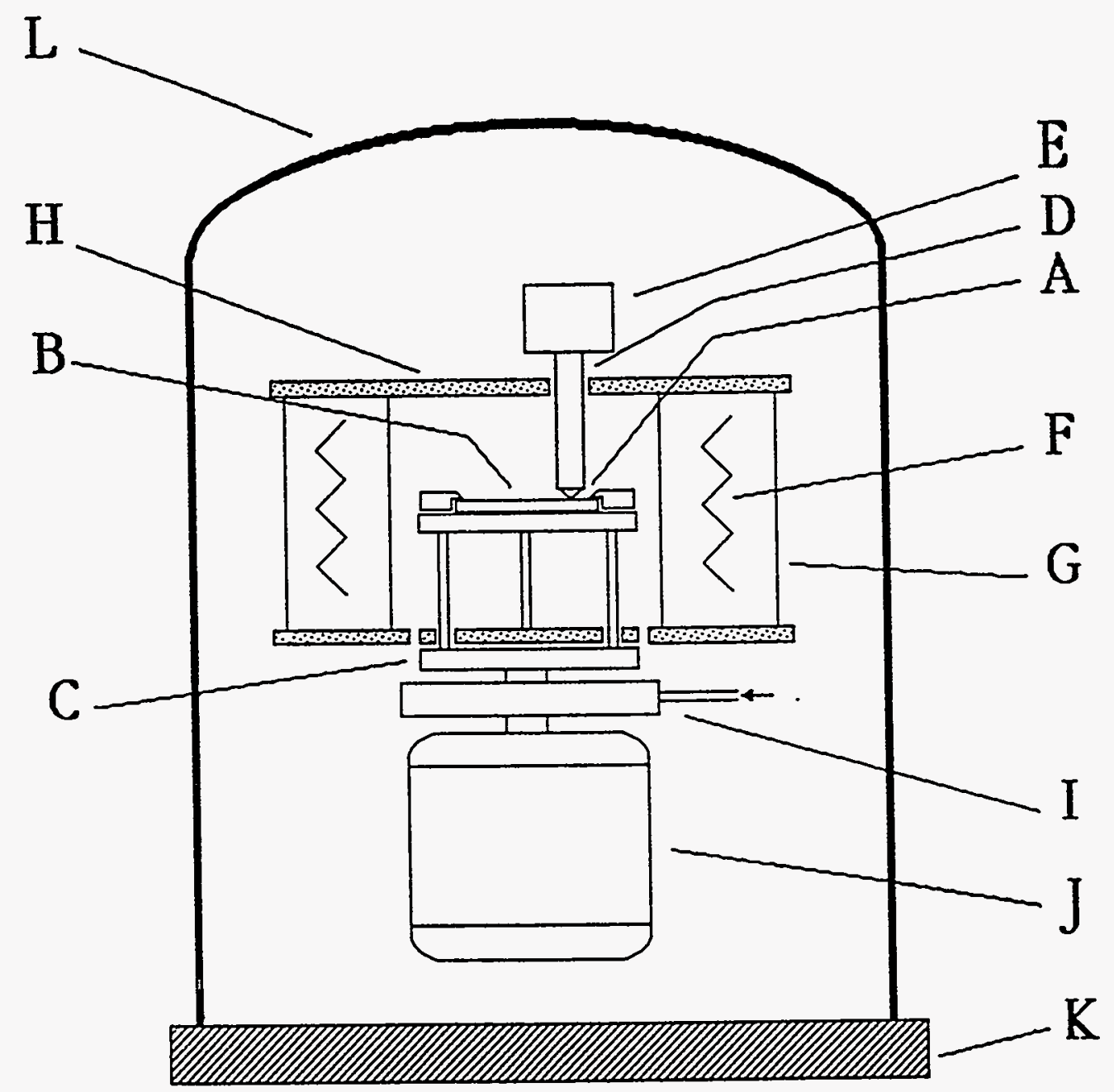

Fig. 1. Schematic diagram of the high temperature tribotest system. A. pin specimen, B. disk specimen, C. base plate for specimen stage, D. mounting rod for pin specimen, E. dead weight, F. resistance heating coils, G. gold-coated reflector, $H$. insulating plate, I. water cooling for the base plate, J. drive motor, $\mathrm{K}$. aluminum base plate for the machine, L. glass bell jar. 


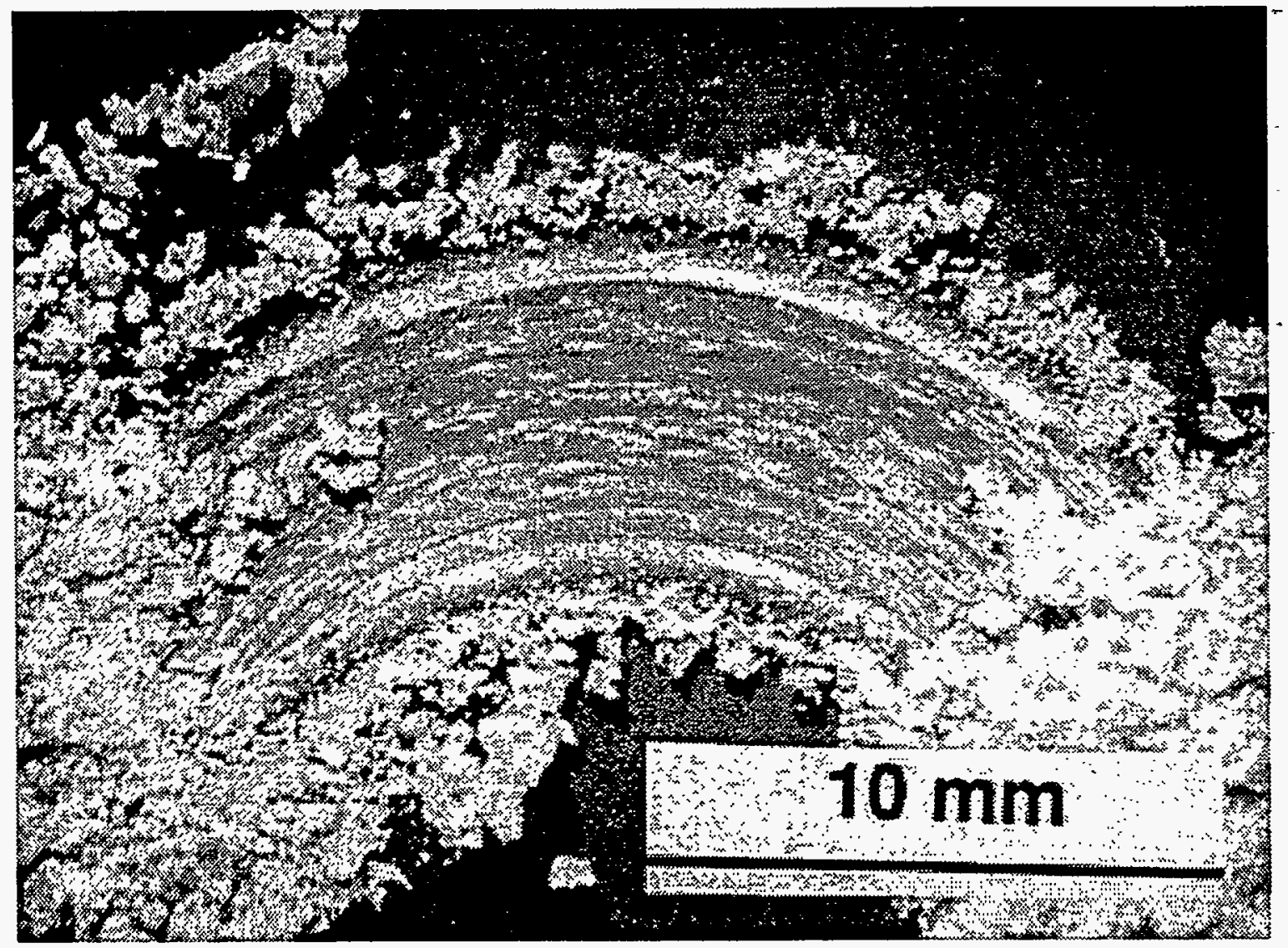

Fig. 2. Optical micrograph of the wear groove formed in an unlubricated test of GS-44 at $900 \mathrm{C}$ in air. Wear debris is evident along the sides of the wear track and as accumulations at each end of the track. 


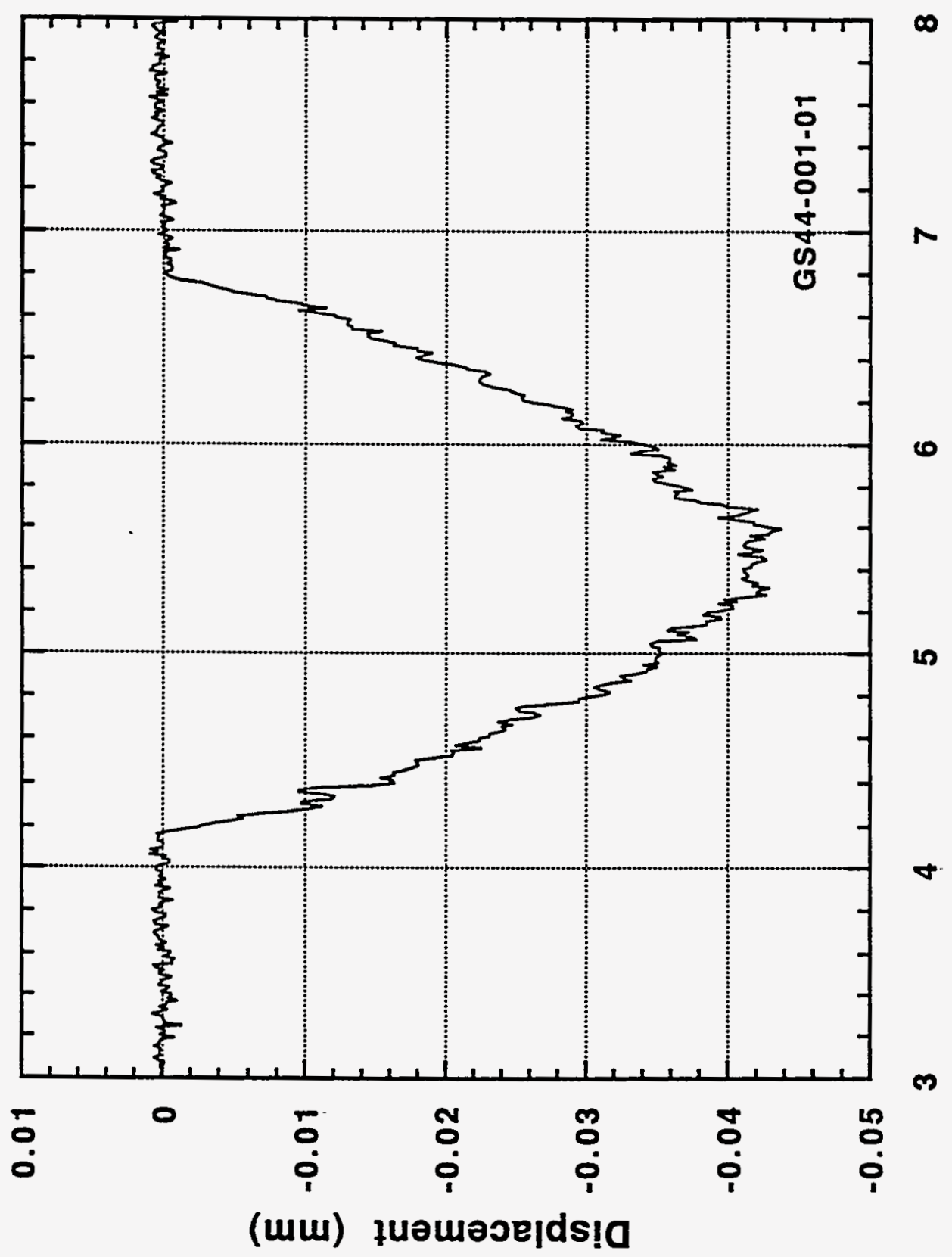

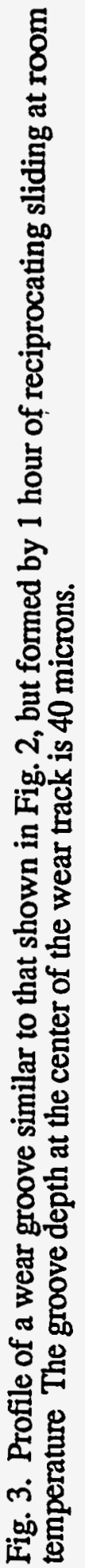




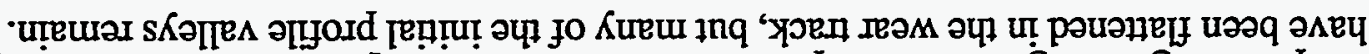

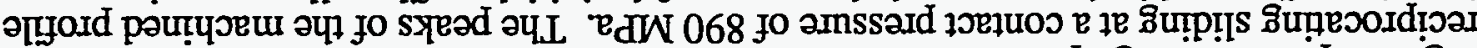

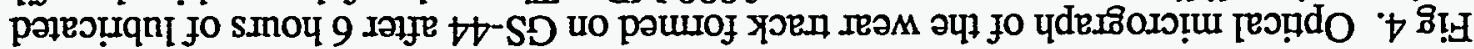

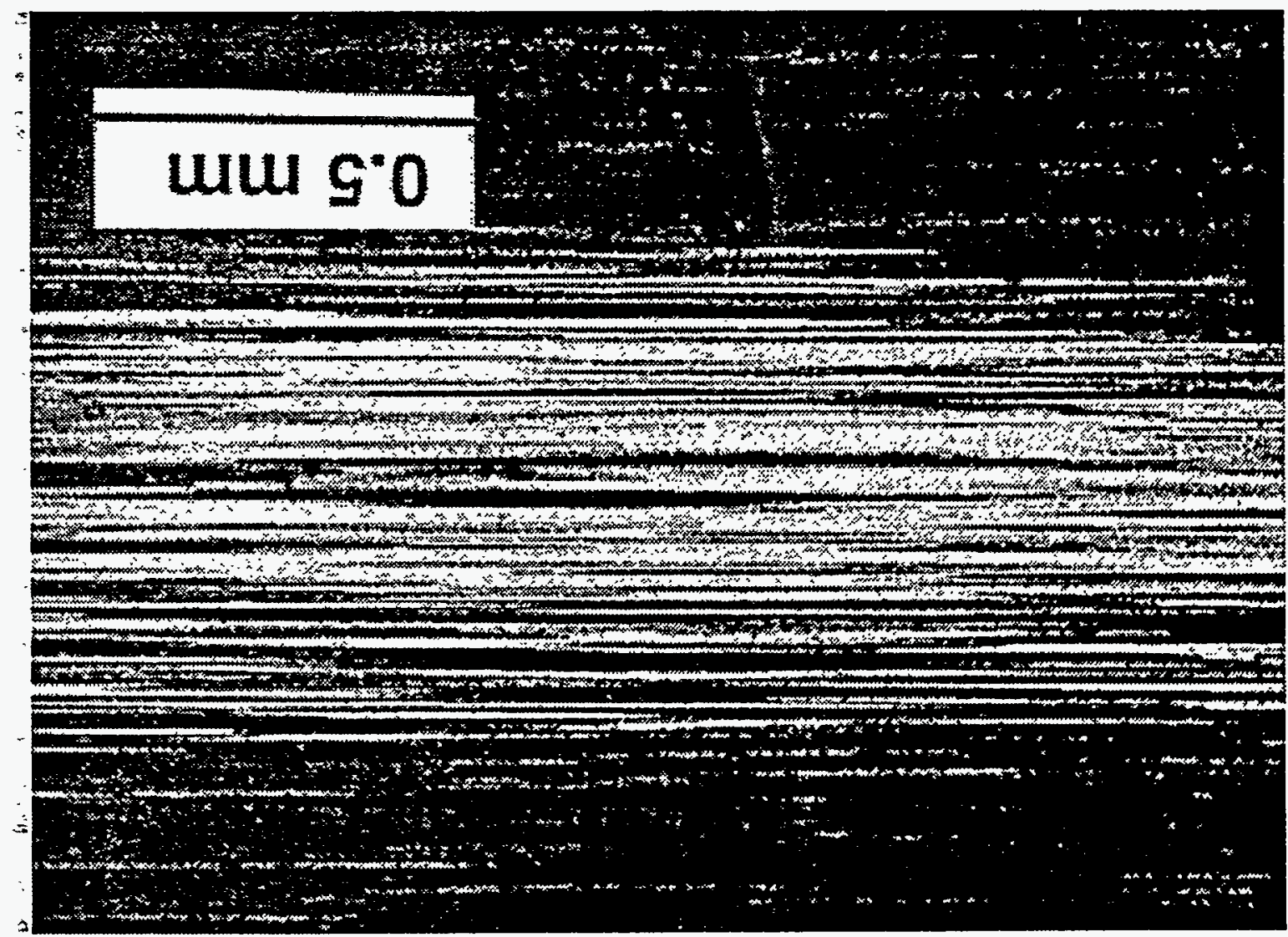




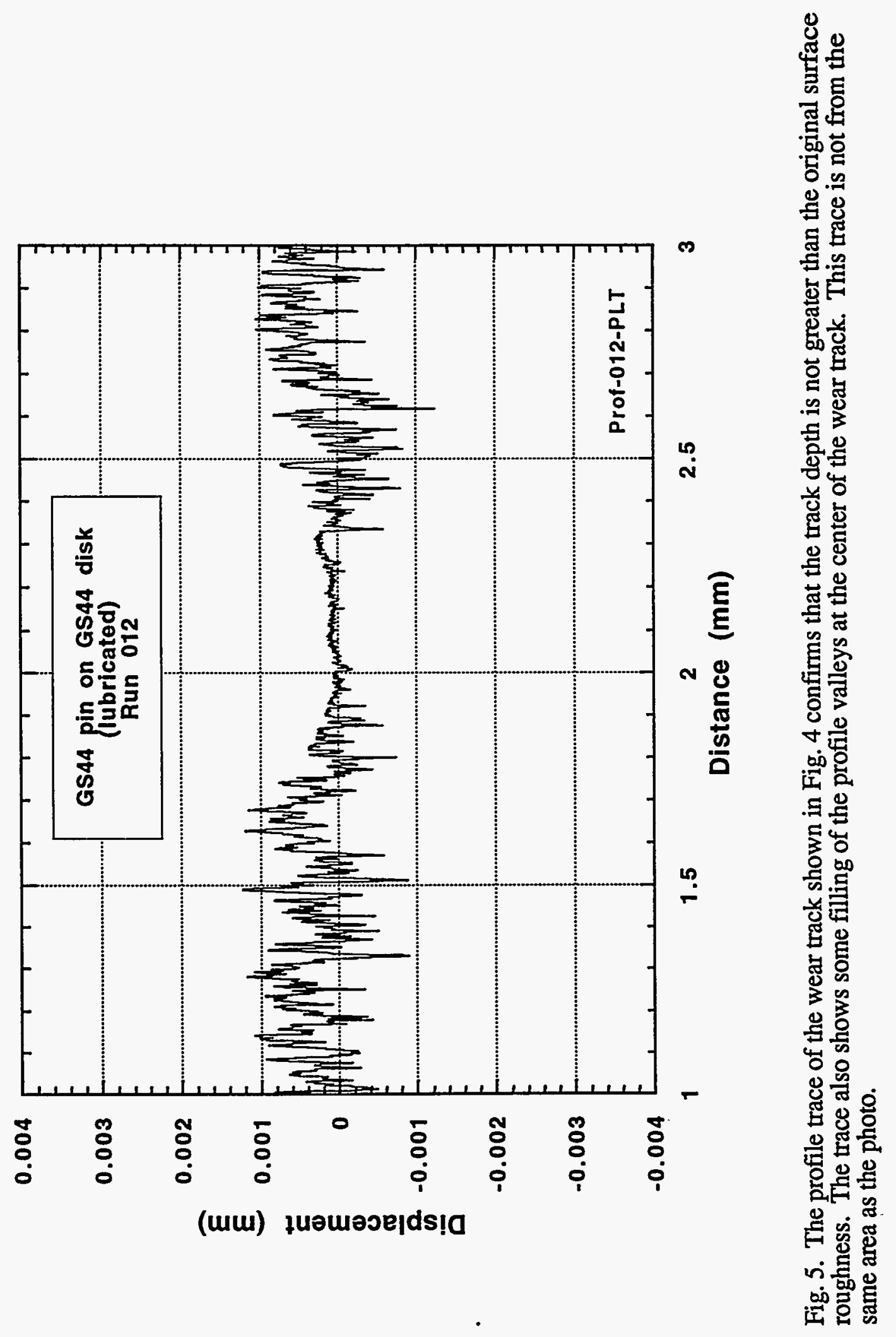




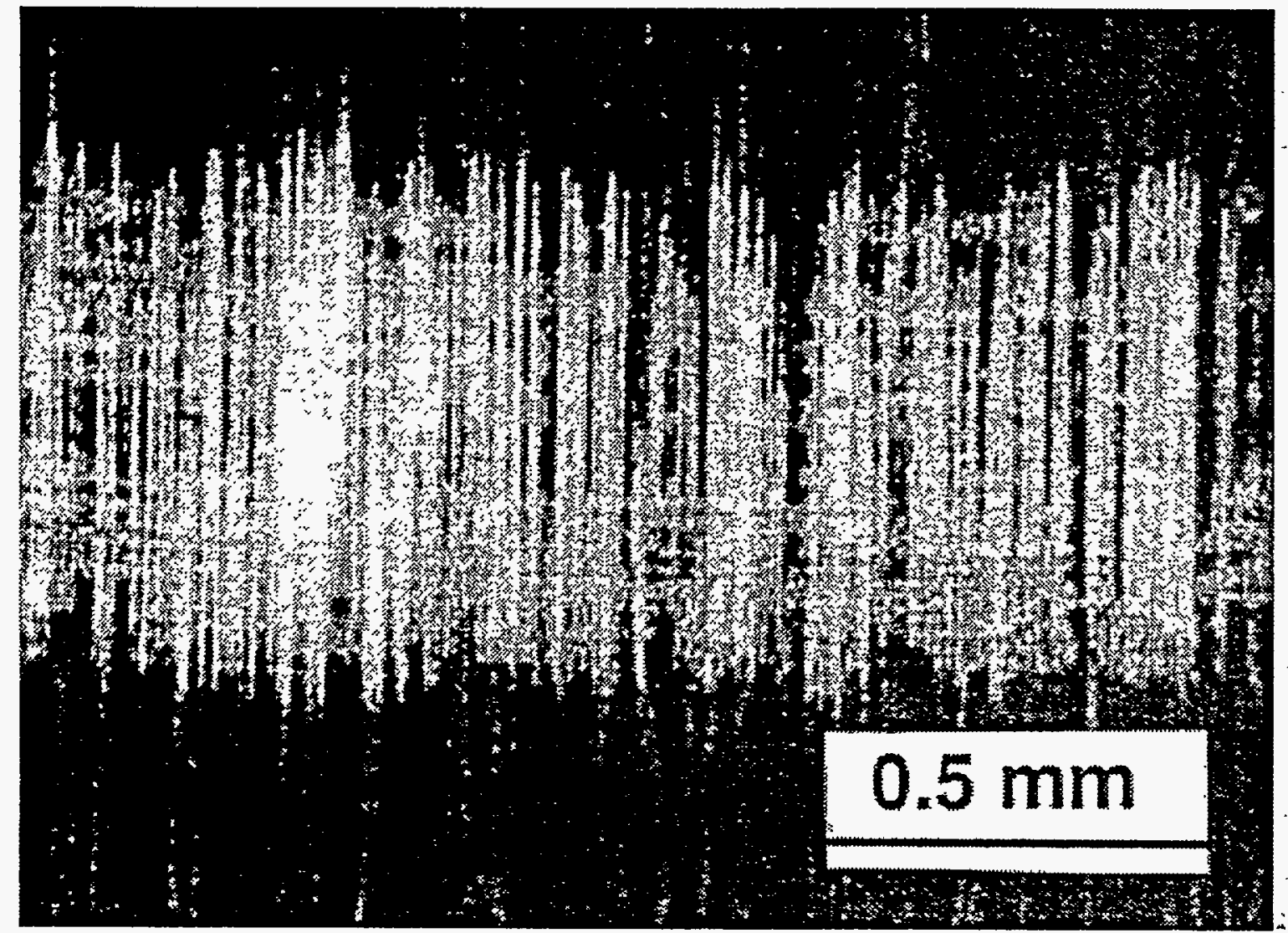

Fig. 6. Optical micrograph of the wear track formed on GN-10 after 6 hours of lubricated reciprocating sliding at a contact pressure of $890 \mathrm{MPa}$. The peaks and valleys of the original profile are plainly seen in this orientation of the wear track with respect to the machining direction. 

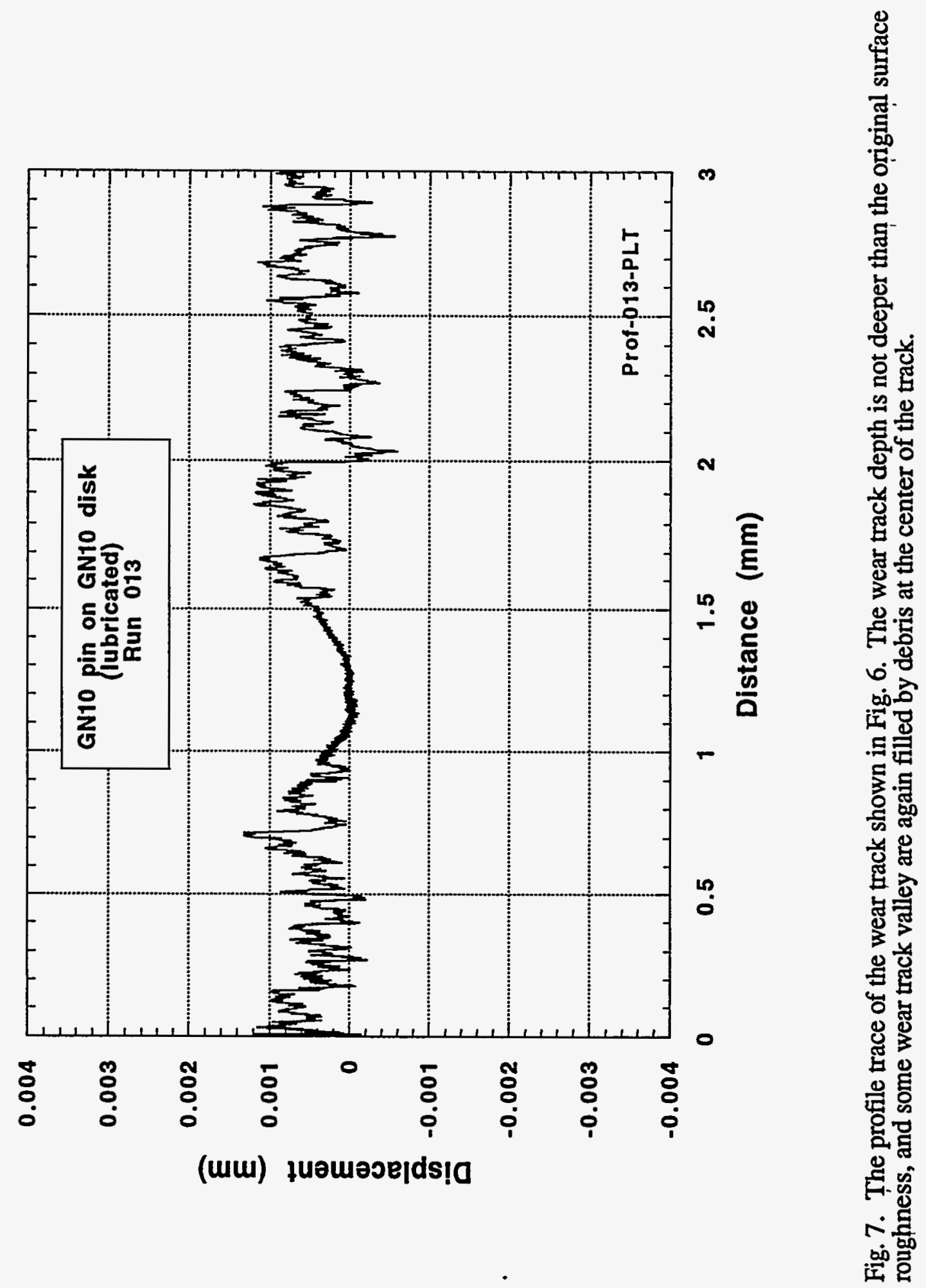


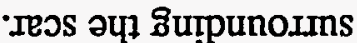

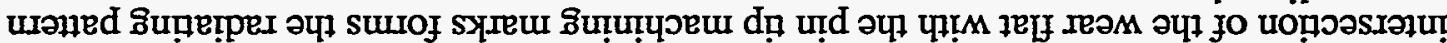

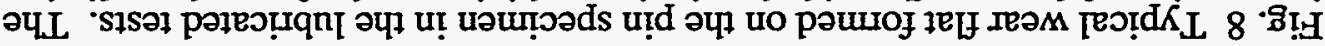

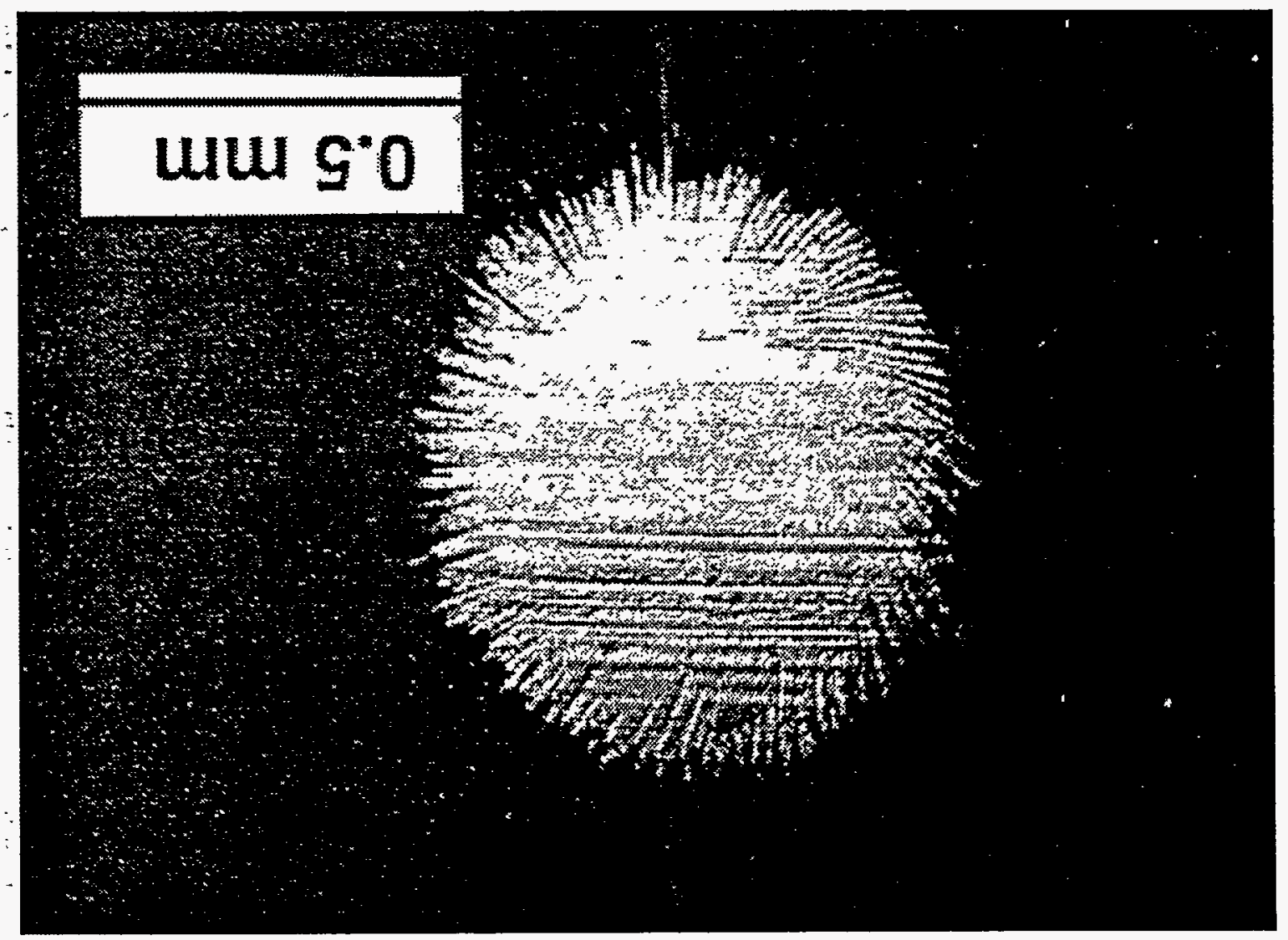




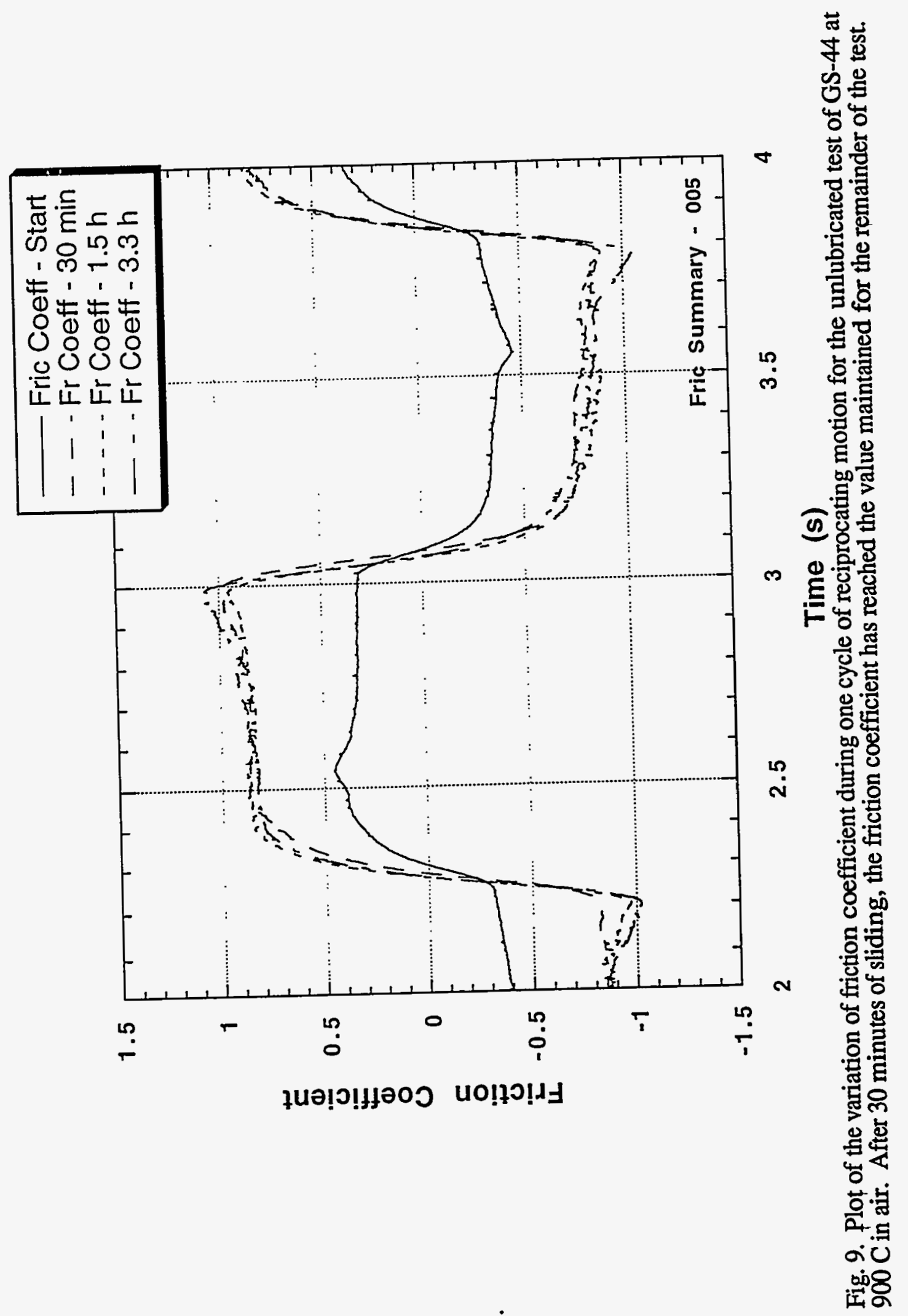

